\title{
AN ADAPTIVE NONLINEAR FUEL INJECTION CONTROL ALGORITHM FOR MOTORCYCLE ENGINE
}

Tung-Chieh Chen

Graduate Student, Department of Vehicle Engineering, National Pingtung University of Science and Technology, Pingtung, Taiwan

Chiu-Feng Lin

Associate Professor, Department of Vehicle Engineering, National Pingtung University of Science and Technology, Pingtung, Taiwan

Chyuan-Yow Tseng

Associate Professor, Department of Vehicle Engineering, National Pingtung University of Science and Technology, Pingtung, Taiwan

Chung-Ying Chen

Doctoral Student, Department of Mechanical and Electro-Mechanical Engineering, National Sun Yat-sen University, Kaohsiung, Taiwan

Follow this and additional works at: https://jmstt.ntou.edu.tw/journal

Part of the Engineering Commons

\section{Recommended Citation}

Chen, Tung-Chieh; Lin, Chiu-Feng; Tseng, Chyuan-Yow; and Chen, Chung-Ying (2005) "AN ADAPTIVE NONLINEAR FUEL INJECTION CONTROL ALGORITHM FOR MOTORCYCLE ENGINE," Journal of Marine Science and Technology. Vol. 13: Iss. 4, Article 2.

DOI: $10.51400 / 2709-6998.2118$

Available at: https://jmstt.ntou.edu.tw/journal/vol13/iss4/2

This Research Article is brought to you for free and open access by Journal of Marine Science and Technology. It has been accepted for inclusion in Journal of Marine Science and Technology by an authorized editor of Journal of Marine Science and Technology. 
AN ADAPTIVE NONLINEAR FUEL INJECTION CONTROL ALGORITHM FOR MOTORCYCLE ENGINE

Acknowledgements

The study was supported by National Science Council of Taiwan under the granted funding of NSC922623-7-202-001-ET. 


\title{
AN ADAPTIVE NONLINEAR FUEL INJECTION CONTROL ALGORITHM FOR MOTORCYCLE ENGINE
}

\author{
Tung-Chieh Chen**, Chiu-Feng Lin*, Chyuan-Yow Tseng**, and Chung-Ying Chen***
}

Key words: adaptive control, fuel injection, observer, nonlinear control.

\section{ABSTRACT}

The purpose of this research is to apply an adaptive fuel injection control algorithm on a motorcycle engine and evaluate its performance. A highly nonlinear switching type EGO sensor is used to measure the air fuel ratio of the engine. In the research, the nonlinear control algorithm is developed based on a Lyapunov function. Furthermore, an observer is also applied to estimate the air flow rate into the combustion room. The results show that the air fuel ratio and engine speed are stable under steady manoeuvres and the air-fuel ratio values are satisfactory.

\section{INTRODUCTION}

Fuel injection control is an important tool for the motorcycle to improve its emission and fuel efficiency performance. The main target of fuel injection control is to achieve a desired Air-Fuel Ratio (AFR) such that the engine power and emission can be compromised. Another reason for AFR control is that the three-way catalytic converter has best performance when the AFR equals to 14.7 .

The fuel injection control is basically a nonlinear and time varying control task [11]. Many different algorithms have been proposed to achieve desired control performance. To derive a control algorithm, engine dynamics model is usually required. Previously, many engine dynamics models have been developed. These models include sophisticated models and gray box models. The sophisticated models describe the mixture formation phenomena including the intake manifold

Paper Submitted 03/24/05, Accepted 06/03/05. Author for Correspondence: Chiu-Feng Lin. E-mail: chiufeng@mail.npust.edu.tw.

*Associate Professor, Department of Vehicle Engineering, National Pingtung University of Science and Technology, Pingtung, Taiwan.

**Graduate Student, Department of Vehicle Engineering, National Pingtung University of Science and Technology, Pingtung, Taiwan.

***Doctoral Student, Department of Mechanical and Electro-Mechanical Engineering, National Sun Yat-sen University, Kaohsiung, Taiwan. dynamics, the torque generation dynamics, and fuel flow dynamics [12]. On the other hand, the gray box models were developed by $[1,7]$. These models were developed using system identification schemes and are suitable for on-line AFR control operation.

As to the control system structure, feed-back incorporated with feed-forward control algorithms are usually adopted. The feed-forward control uses a lookup table relating desired fuel injection rate to engine loading and engine speed [2,9]. On the other hand, feed-back control loop receives feedback signal to correct the transient AFR error. It is straight forward to use AFR as the feedback signal and many researches were focus on the accuracy of the AFR measurement [17]. For the feedback control loop, many algorithms to deal with the engine nonlinearity were proposed. Examples are the sliding mode control algorithms $[3,10]$ and the feedback linearizing AFR control algorithm [5]. Furthermore, since the engine characteristics are time varying, [8, 13] include state observers, [4, 16] apply adaptive system parameter identification law to improve the transient dynamics.

The above control algorithms seem to work for car engines. However, they are complicated and may not work for motorcycle engines. This is because motorcycle engines usually operate at higher speed and therefore have different dynamics characteristics. Therefore, a suitable algorithm for the motorcycle engine fuel injection control is the goal of this research. The following section introduces the dynamics model for this research. Section 3 discusses the proposed adaptive control algorithm. Section 4 presents the experiment setup to validate the proposed adaptive control algorithm. Finally, section 5 presents the results of the validation.

\section{DYNAMICS MODELS}

\section{Motorcycle longitudinal dynamics model}

The motorcycle longitudinal dynamics can be described by the bond graph model [14] in Figure 1. In 
which, $T_{e}$ is the engine output torque, $b_{e}$ is the crank shaft bearing friction coefficient, $\omega_{e}$ is the engine speed, $\omega_{w}$ is the motorcycle rear wheel speed, $g_{r}$ is the transmission gear ratio, $r_{w}$ is the rear wheel radius, $u$ is the motorcycle forward speed, $T_{r}$ is the rear wheel rolling resistance, $J_{t}$ is the moment inertia of the rear wheel, $m_{s}$ is the motorcycle mass including the rider, $F$ is the interactive force between the tire and the ground, $F_{g}$ is the resistance due to slope, and $F_{a}$ is the aero drag force. Then the motion equation of the motorcycle longitudinal dynamics can be written as

$$
\left(J_{t}+r_{w}^{2} m_{s}\right) \dot{\omega}_{w}=\left(T_{e}-b_{e} \omega_{e}\right) g_{r}-T_{r}-r_{w} F_{a}-r_{w} F_{g}
$$

\section{Engine dynamics model}

Engine dynamics includes intake manifold dynamics, fuel flow dynamics, and torque generation dynamics $[12,18]$. These dynamics are discussed subsequently.

\subsection{Intake manifold dynamics}

Intake manifold dynamics can be expressed as

$$
\dot{m}_{a}=\dot{m}_{a i}-\dot{m}_{a o}
$$

In which, $\dot{m}_{a}$ is the air flow rate in the intake manifold volume, $\dot{m}_{a i}$ is the air flow rate into the intake manifold, and $\dot{m}_{a o}$ is the air flow rate into the combustion room. The air flow rate into the intake manifold can be expressed as

$$
\dot{m}_{a o}=M A X \times T C \times P R I
$$

In Eq. (3), MAX is the maximum air flow rate, $T C$ accounts for the throttling effect, $P R I$ is a function of the air pressure before and behind the throttle. Besides, the air flow into the combustion room is described in Eq. (4). In which $\eta_{v}$ is the volumetric efficiency, $\omega_{e}$ is the engine speed ( $\mathrm{rad} / \mathrm{sec}), c$ is defined in Eq. (5), $V_{e}$ is the cylinder volume.

$$
\begin{aligned}
& \dot{m}_{a o}=c \eta_{v} \omega_{e} m_{a} \\
& c=\frac{V_{e}}{4 \pi V_{m}}
\end{aligned}
$$

\subsection{Torque generation model}

Engine torque generation dynamics can be expressed as

$$
T_{e}=C_{T} \frac{\dot{m}_{a o}\left(t-\Delta t_{i t}\right)}{\omega_{e}\left(t-\Delta t_{i t}\right)} A F I\left(t-\Delta t_{i t}\right) S I\left(t-\Delta t_{s t}\right)
$$

In Eq. (6), $T_{e}$ is the engine indicative torque, $C_{T}$ is a constant, $S I$ is a function of the fuel injection timing, $A F I$ is a function of AFR, $\Delta t_{i t}$ is the time delay between air intake and torque generation, $\Delta t_{s t}$ is the time delay between ignition and torque generation.

\subsection{Fuel flow dynamics}

The fuel flow dynamics can be expressed as

$$
\begin{aligned}
& \ddot{m}_{f f}=\frac{1}{\tau}\left(-\dot{m}_{f f}+\xi \dot{m}_{f i}\right) \\
& \dot{m}_{f v}=(1-\xi) \dot{m}_{f i} \\
& \dot{m}_{f v}=(1-\xi) \dot{m}_{f i}
\end{aligned}
$$

In which, $\dot{m}_{f c}$ is the fuel rate into the combustion room, $\dot{m}_{f i}$ is the fuel rate out of the nozzle, $\dot{m}_{f f}$ is the fuel flow directly into the cylinder, $\dot{m}_{f v}$ is the fuel flow from evaporation, $\xi$ is the deposit rate, $\tau$ is the deposition

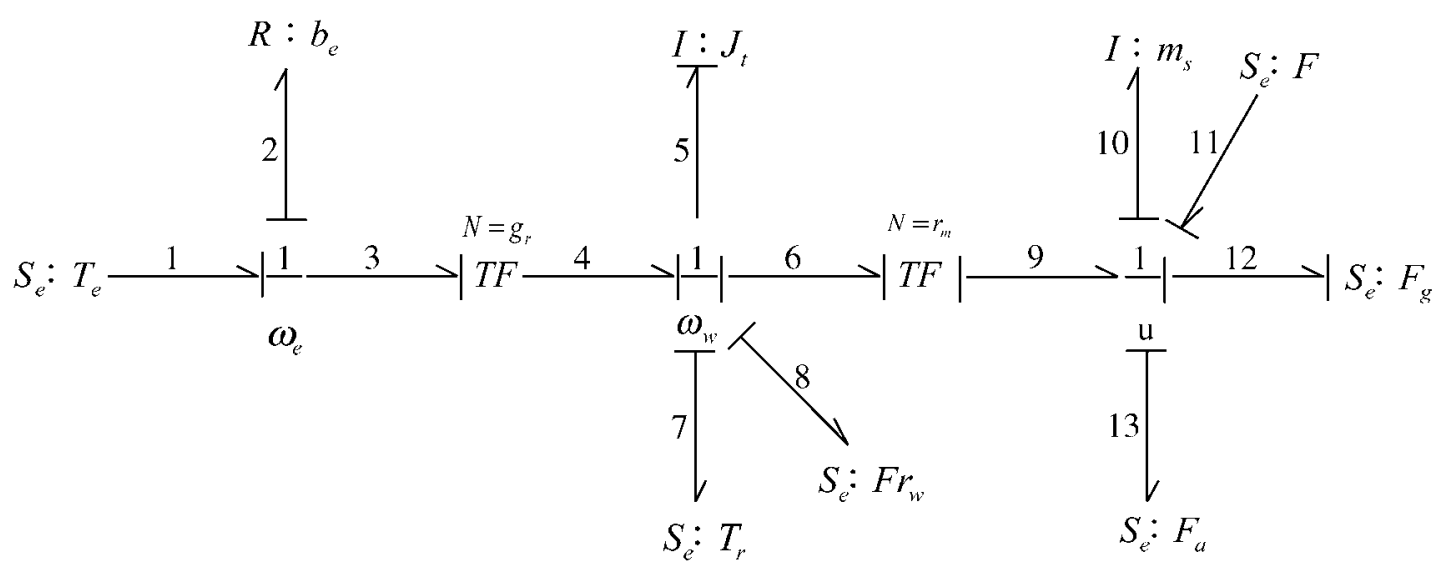

Fig. 1. Motorcycle longitudinal dynamics model. 
coefficient. This is because a portion of $\dot{m}_{f i}$ deposits on the wall in stead of going into the combustion with the intake air. The deposit portion evaporates and then flow into the combustion room in a later time.

\section{ADAPTIVE FUEL INJECTION CONTROL ALGORITHM}

\section{Nonlinear control algorithm}

Suppose an error indicator, $s$, is defined as the following

$$
s=\dot{m}_{a o}-\beta_{0} \dot{m}_{f c}
$$

where $\beta_{0}$ is the desired AFR. On the other hand, the actual AFR is defined as $\beta=\frac{\dot{m}_{a o}}{\dot{m}_{f c}}$. The error defined in Eq. (10) may converge to zero if the following dynamics can be achieved [15]

$$
s \dot{s}=-\eta|s|-\frac{1}{\tau} s^{2}
$$

where $\eta$ is a gain values chosen to be positive, $\tau$ is the deposition coefficient which is always positive. In theory, $\eta$ affect the convergence rate of the AFR control.

This is because $s^{2}$ converge to zero if $\frac{d}{d t}\left(s^{2}\right)=s \dot{s}<0$.

Furthermore, if $s^{2}$ converge to zero, also converges to zero. In Eq. (11), the right hand size is negative because $\eta, \tau,|s|$, and $s^{2}$ are positive, ensuring $s \dot{s}<0$. From (8), (9), one can write

$$
\dot{m}_{f c}=(1-\xi) \dot{m}_{f i}+\dot{m}_{f f}
$$

By differentiating Eqs. (10) and (12) and then rearrange the results, one can obtain

$$
\begin{aligned}
& \dot{s}=\ddot{m}_{a o}-\beta_{0}\left[(1-\xi) \ddot{m}_{f i}+\frac{1}{\tau} \dot{m}_{f i}-\frac{1}{\tau} \dot{m}_{f c}\right] \\
& \dot{s}=\ddot{m}_{a o}-\beta_{0}\left[(1-\xi) \ddot{m}_{f i}+\frac{1}{\tau} \dot{m}_{f i}-\frac{1}{\beta_{0} \tau} \dot{m}_{a o}\right]-\frac{1}{\tau} s
\end{aligned}
$$

Since EGO sensor is used for most of the motorcycle for the reason of cost reduction. This kind of sensor generates switching type signal. Thus, its output signal is expressed as $y=\operatorname{sgn}(s)$. For the purpose of injecting fuel control, Eq. (11) is chosen as the control algorithm. This equation can be rearranged as

$$
\dot{s}=-\eta \frac{|s|}{s}-\frac{s}{\tau}=-\eta \operatorname{sgn}(s)-\frac{s}{\tau}=-\eta y-\frac{s}{\tau}
$$

Since $y=\operatorname{sgn}(s)$ is the feed-back signal in the real application, the following equation, can be derived

$$
-\eta y=\ddot{m}_{a o}-\beta_{0}\left[(1-\xi) \ddot{m}_{f i}+\frac{1}{\tau} \dot{m}_{f i}-\frac{1}{\tau} \dot{m}_{f c}\right]
$$

Rearrange the above equation, one can obtain

$$
\ddot{m}_{f i}=-\frac{1}{\tau(1-\xi)} \dot{m}_{f i}+\frac{\dot{m}_{a o}}{\tau \beta_{0}(1-\xi)}+\frac{1}{\beta_{0}(1-\xi)}\left(\ddot{m}_{a o}+\eta y\right)
$$

This equation ensures that the AFR converges to the desired value.

\section{Intake air flow rate observer}

As shown in Eq. (17), injected fuel quantity is decided by the air flow rate into the combustion room to achieve desired AFR. However, it is hard to measure air flow rate. Therefore, an observer is proposed to estimate this value.

Suppose the estimate of $\dot{m}_{a o}$ is $\dot{\hat{m}}_{a o}$, the estimate of $\ddot{m}_{a o}$ is $\ddot{\hat{m}}_{a o}$, then the following equation can be established

$$
\ddot{m}_{f i}=\frac{1}{\tau(1-\xi)}\left[-\ddot{m}_{f i}+\frac{1}{\beta_{0}} \dot{\hat{m}}_{a o}+\frac{\tau}{\beta}\left(\ddot{\hat{m}}_{a o}+\eta y\right)\right]
$$

Consequently, one can substitute Eq. (18) into (14) to obtain

$$
\begin{aligned}
\dot{s} & =\ddot{m}_{a o}-\beta_{0}\left\{\frac{1}{\tau}\left[-\dot{m}_{f i}+\frac{1}{\beta_{0}} \dot{\hat{m}}_{a o}+\frac{\tau}{\beta_{0}}\left(\ddot{\hat{m}}_{a o}+\eta y\right)\right]\right. \\
& \left.+\frac{1}{\tau} \dot{m}_{f i}-\frac{1}{\beta_{0} \tau} \dot{m}_{a o}\right\}-\frac{1}{\tau} s
\end{aligned}
$$

Then, rearrange the above equation to obtain

$$
\dot{s}=\left(\ddot{m}_{a o}-\ddot{\hat{m}}_{a o}\right)+\frac{1}{\tau}\left(\dot{m}_{a o}-\dot{\hat{m}}_{a o}\right)-\eta y-\frac{1}{\tau} s
$$

If the following Lyapunov function [15] is applied

$$
V=|s|+\frac{1}{2}\left(\eta_{v}-\hat{\eta}_{v}\right)^{2}
$$

where $\eta_{v}$ is the volumetric efficiency and $\hat{\eta}_{v}$ is its estimate, the following equation can be obtained by differentiating Eq. (21)

$$
\dot{V}=\dot{s} \operatorname{sgn}(s)-\left(\eta_{v}-\hat{\eta}_{v}\right) \dot{\hat{\eta}}_{v}
$$

The Lyapunov function in Eq. (21) is a specially designed function to facilitate our design of a nonlinear controller under the use of a switching type EGO 
sensor. This is because EGO sensor for measuring the AFR only provide "too high" or "too low" information, represented by " 1 " and "-1" relatively. The above signal from EGO sensor can be represented by $\operatorname{sgn}(s)$ mathematically. Thus, for the purpose of designing a suitable adaptive law, a $|s|$ is used in the Lyapunov function. Furthermore, the $\frac{1}{2}\left(\eta_{v}-\hat{\eta}_{v}\right)^{2}$ term in Eq.

is to ensure that the volumetric efficiency estimate converges to the correct value as time goes to infinity. Then, substitute Eq. (20) into Eq. (22) to acquire

$$
\begin{aligned}
\dot{V} & =\left[\left(\ddot{m}_{a o}-\ddot{\hat{m}}_{a o}\right)+\frac{1}{\tau}\left(\dot{m}_{a o}-\dot{\hat{m}}_{a o}\right)-\eta y-\frac{1}{\tau} s\right] \operatorname{sgn}(s)_{v} \\
& -\left(\eta_{v}-\hat{\eta}_{v}\right) \dot{\hat{\eta}}_{v}
\end{aligned}
$$

Supposed the following adaptive law is selected

$$
\dot{\hat{\eta}}_{v}=\frac{1}{\tau} c \omega_{e} m_{a} \operatorname{sgn}(s)
$$

in which $\omega_{e}, m_{a}$, and $\operatorname{sgn}(s)$ are measured variables from relative sensors. Eq. (23) can be rewritten as

$$
\dot{V}=\left[\left(\ddot{m}_{a o}-\ddot{\hat{m}}_{a o}\right)-\eta y-\frac{1}{\tau} s\right] \operatorname{sgn}(s)
$$

When the engine is under minor operation, $\ddot{m}_{a o}$ is almost zero, which approximate $\ddot{\hat{m}}_{a o}$ to $c \dot{\eta}_{v} \omega_{e} m_{a}$. Furthermore, from Eq. (24), $\ddot{\hat{m}}_{a o}$ is always positive. Thus, Eq. (25) can be written as

$$
\dot{V}=-\ddot{\tilde{m}}_{a o} \operatorname{sgn}(s)-\eta \operatorname{sgn}^{2}(s)-\frac{1}{\tau}|s|
$$

which is always a negative value due to the above mentioned reason. Furthermore, since Eq. (21) reveals that is always positive, always converges to zero if Eq. (26) is achieved. This proves that the adaptive nonlinear control algorithm is stable.

\section{EXPERIMENTAL SETUP}

To validate the proposed algorithm, a hardwarein-the-loop motorcycle longitudinal dynamics simulator is applied. The simulator features the dynamics of KYMCO AFI125 motorcycle. The specification of the motorcycle is shown in Table 1. This simulator includes an engine, a transmission, and a rear wheel from a real motorcycle. A powder brake is rigidly coupled to the rear wheel to generate effective road loading on the rear wheel. The effective road loading is expressed as

$$
T_{e f f}=T_{r}+r_{w} F_{g}+r_{w} F_{a}
$$

A fly wheel is coupled to the rear wheel to account for the effective inertia of the motorcycle. A central computer is applied to control the operation of the system, including the operation of the throttle variation and the powder brake torque generation. The central computer is also responsible for dynamics variables measurement. Another computer embedded with Mathworks XPC is used to control the fuel injection. The proposed adaptive control algorithm is realized through Matlab/Simlink/State flow software. A picture of the motorcycle dynamics simulator is shown in Figure 2. On the dynamics simulator, sensors are installed to acquire the corresponding dynamics variables, including a engine speed sensor, engine brake torque sensor, rear wheel speed sensor. Finally, a BOSCH ETP-008.71 five gas emission analyzer was used to measure the emission of the engine.

\section{RESULTS AND DISCUSSIONS}

To validate the proposed algorithm, several differ-

Table 1. Specification of KYMCO AFI125

\begin{tabular}{ll}
\hline Body model & SJ25AA \\
Height, width, length & $1,115,695,1770 \mathrm{~mm}$ \\
Engine model & AFI SR125 \\
Engine type & 4 stroke, air cooled, OHC \\
Engine bore, stroke & $52.4,57.8 \mathrm{~mm}$ \\
Engine fuel system & Fuel injection \\
Engine no. of valves & 2 \\
Engine displacement volume & $124.6 \mathrm{cc}$ \\
Engine compression Ratio & 9.8 \\
Engine idle speed & $1640 \mathrm{rpm}$ \\
Engine ignition type & $\mathrm{CDI}$ \\
Transmission & $\mathrm{CVT}$ \\
\hline
\end{tabular}

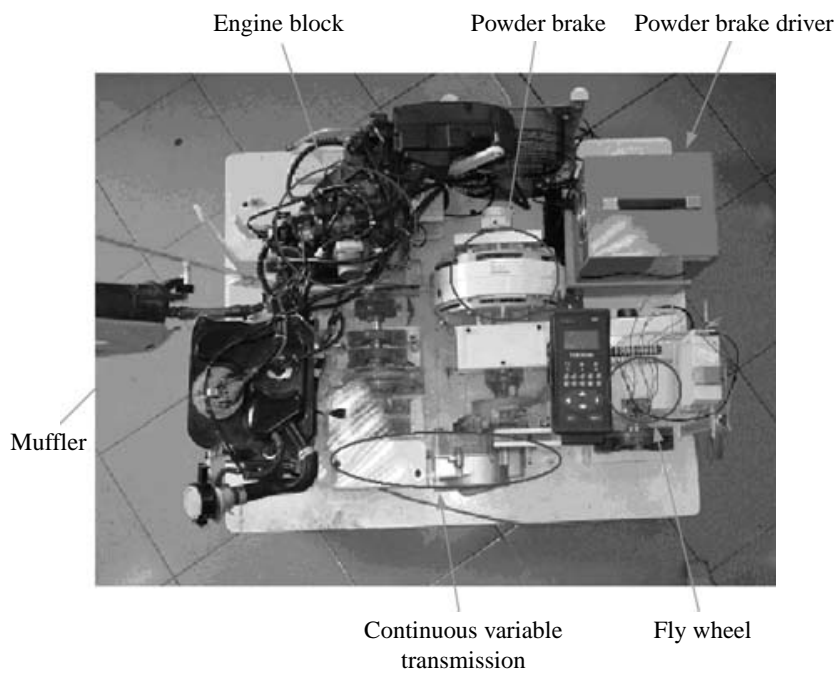

Fig. 2. Motorcycle longitudinal dynamics simulator. 
ent simulations were conducted. These simulations characterize the performance of the intake air flow rate observation. Since the features of these simulations are similar, only one simulation result is presented in this paper.

The presented simulation has an initial $20^{\circ}$ steady state manoeuvring followed by a step throttling change of $20^{\circ}$ at $40 \mathrm{sec}$ and maintain at $40^{\circ}$ after the change. Figure 3 shows the motorcycle speed variation in this case. In the initial stage, the vehicle speed rise to a steady speed at about $24 \mathrm{~km} / \mathrm{h}$. Then, at $40 \mathrm{sec}$ the motorcycle speed increase to a new steady speed. Figure 4 shows the volumetric efficiency estimation using the observation law. Since the volumetric efficiency has direct relation with the intake air flow rate, Figure 4 also characterizes the performance of intake air flow observation. In the simulation, the initial estimate has

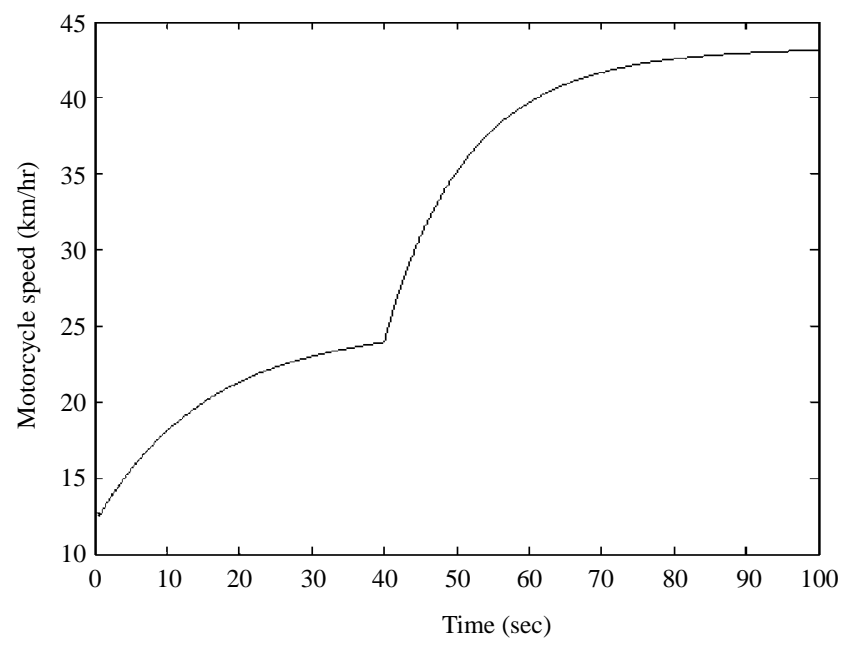

Fig. 3. Motorcycle speed variation in step manoeuvring simulation.

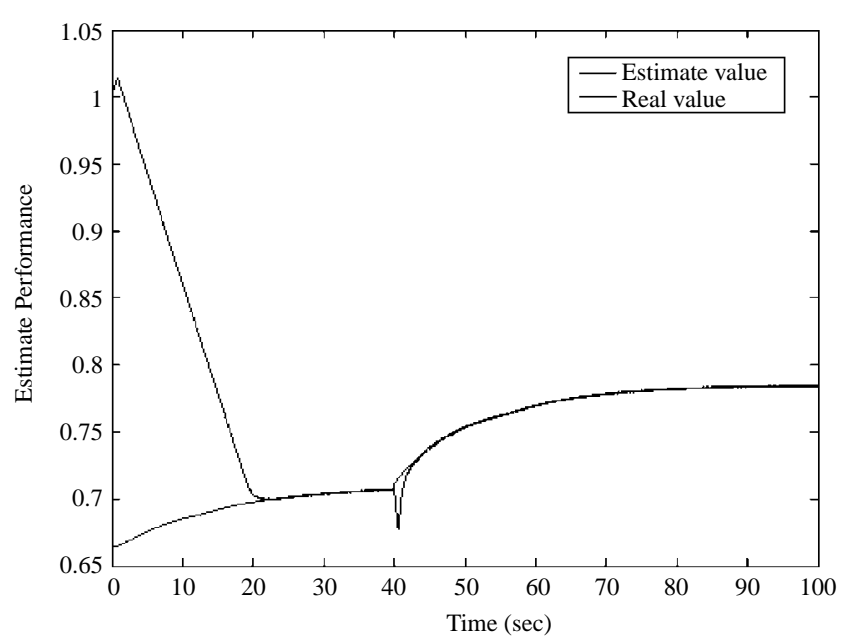

Fig. 4. Volumetric efficiency estimation in step manoeuvring simulation. a significant deviation from the real value. Then, the estimated volumetric efficiency converges to the correct value in about $20 \mathrm{sec}$. At $40 \mathrm{sec}$, the estimate value diverges from the correct value again due to the step manoeuvring. However, it converges to the correct value in an instance. It can be expected that after the first convergence, the estimation error can be corrected instantly. Finally, Figure 5 shows the air-fuel ratio variation in this case. Initially, a substantial air-fuel ratio deviation exists due to the initial intake air estimation error. Then, the AFR converge to the desired value in about $20 \mathrm{sec}$, which is closely correlated to the performance of the intake air estimation. Finally, the step manoeuvre at $40 \mathrm{sec}$ also introduces an AFR deviation. The AFR control algorithm quickly corrects the deviation. The above figures show that the proposed adaptive law is expected to perform well if the dynamics can be modelled accurately. However, modelling error is expected and, thus, the adaptive law performance is expected to degrade on real engine.

Subsequently, experiments were also conducted to evaluate the performance of the control algorithm applying on motorcycle engine. For the experimental validation, several experiments were conducted and the results are similar. Therefore, some of the experiment results are presented in this paper. First of all, the performance of volumetric efficiency observation is evaluated. A result corresponding to an idle speed operation is shown in Figure 6. This figure shows that the observation starts at $30 \mathrm{sec}$ and the volumetric efficiency converges to a steady state value, with a significant initial deviation. This is reasonable since the air flow rate is stable in steady state operation. This result validates the performance of the adaptation law. Then, the performance of the adaptive nonlinear control

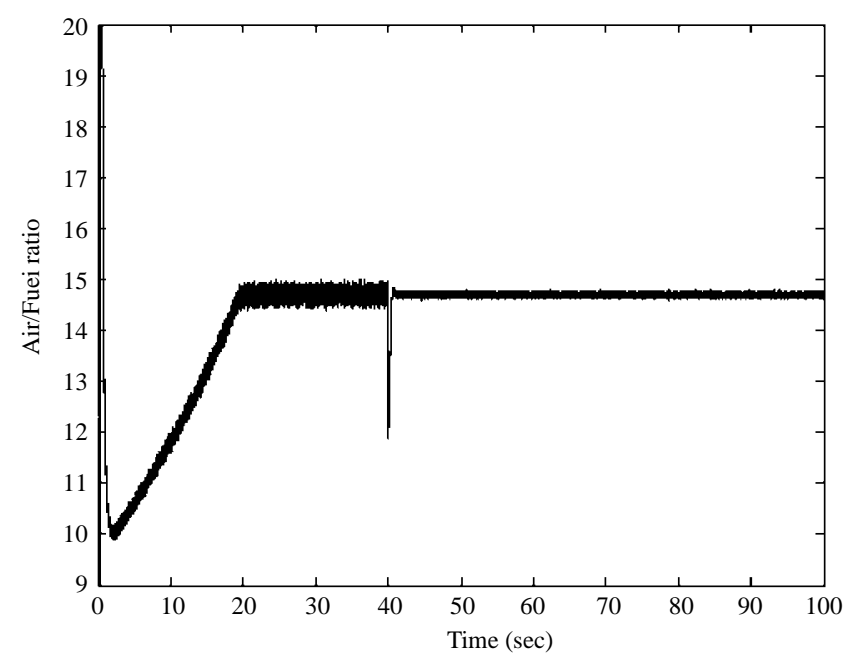

Fig. 5. Air-fuel ratio variation in step manoeuvring simulation. 
law is compared with the open-loop control law used on the KYMCO motorcycle. The open-loop KYMCO controller is basically a series of look-up table incorporated with many logic rules to switch between different tables for different operation condition. Compensation rules are also integrated in the controller to compensate for environmental variation such as different environmental temperatures. These tables are usually developed through a tedious tuning in the cost of man-power and development time period. On the other hand, the adaptive nonlinear controller can adapt to different engine and different operation condition in a short period. Basically, it does not require pre-tuning of the engine. Furthermore, for the open-loop type controller, re-tuning is usually required for an aging engine, which does not apply to the adaptive nonlinear controller. Thus, the adaptive nonlinear controller is a relatively better control algorithm from the commercialization point of view.

Figures 7 and 8 show the results in idle operation of the KYMCO controller and the adaptive nonlinear controller relatively. In each figure, throttle, speed, and air-fuel ratio variations are shown. One can see that the engine speeds in these two experiments are both stable, which implies that the air-fuel ratio in both cases must also be stable. Measurements of the air-fuel ratio in these two cases are also shown in Figures 7 and 8. The results show that the air-fuel ratios are stable as expected. However, the air-fuel ratio of the adaptive nonlinear controller is relatively smoother than the KYMCO controller. This is because the adaptive nonlinear controller is capable of resolving the dynamics variation in the system.

Furthermore, steady state operations featuring engine speed roughly about $3000 \mathrm{rpm}$ were also conducted for both the KYMCO controller and the adaptive

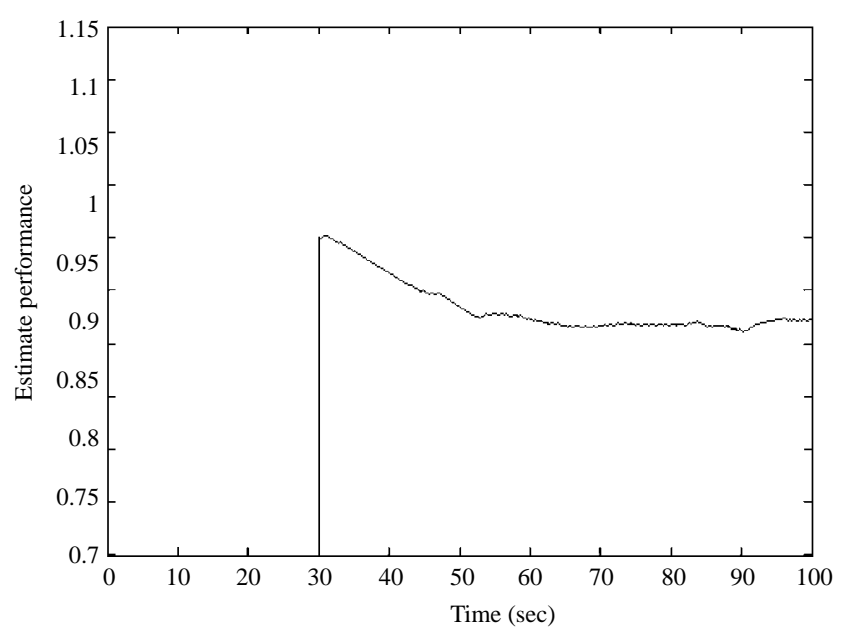

Fig. 6. Volumetric efficiency observation in an idle operation. nonlinear controller. The results are shown in Figures 9 and 10. Similar results as that shown in the idle operation were obtained. However, for the adaptive nonlinear controller, two significant deviations can be noticed between 25 and $30 \mathrm{sec}$. This situation happens due to the measurement error in the intake manifold pressure, which causes an error in the calculation of $m_{a}$, and consequently, error in the calculation of $\dot{\eta}_{v}$ in Eq. (24). This error introduces error in the calculation of injecting fuel. To improve this situation, an appropriate filter may be used to get rid of the measurement noise in the intake manifold pressure sensing. Another way to deal with this problem is to develop a robust controller reduce the sensitivity of the close-loop system to the measurement noise.

Finally, CO, HC, and NO are measured while testing the adaptive nonlinear controller and the aver-

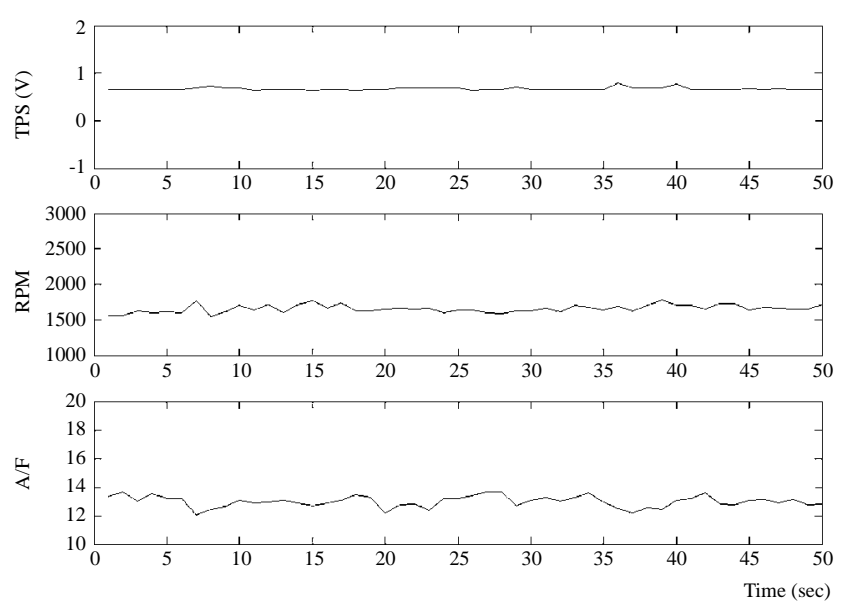

Fig. 7. Performance of KYMCO motorcycle controller in idle operation.
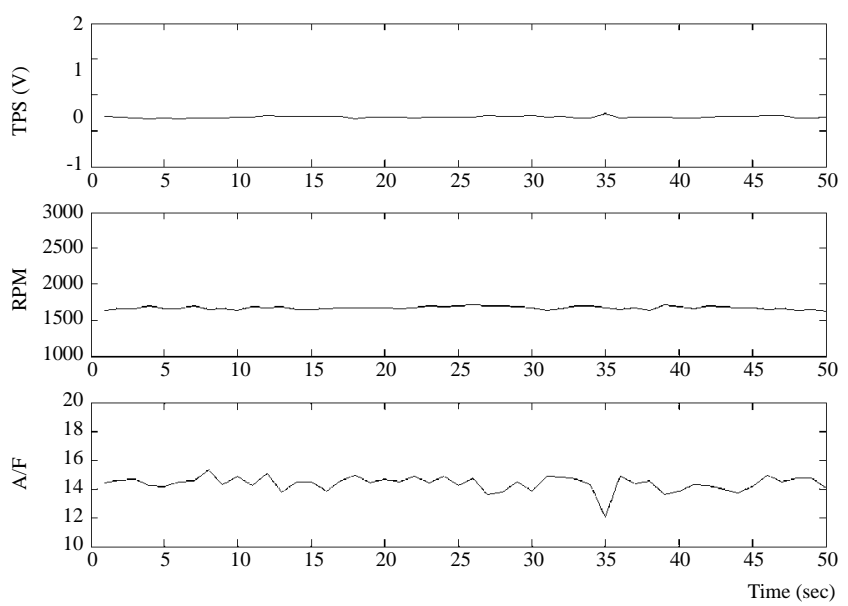

Fig. 8. Performance of the adaptive nonlinear motorcycle controller in idle operation. 

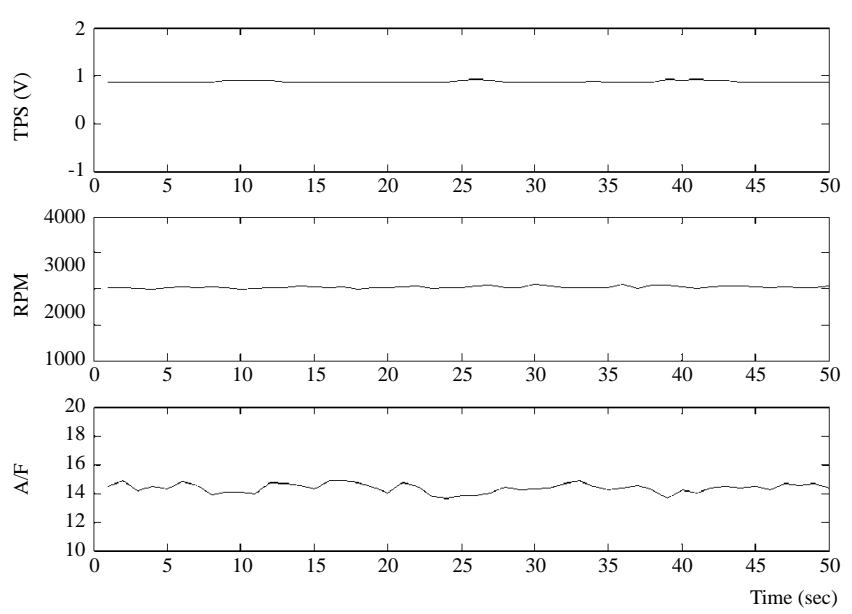

Fig. 9. Performance of KYMCO motorcycle controller in a steady state operation.
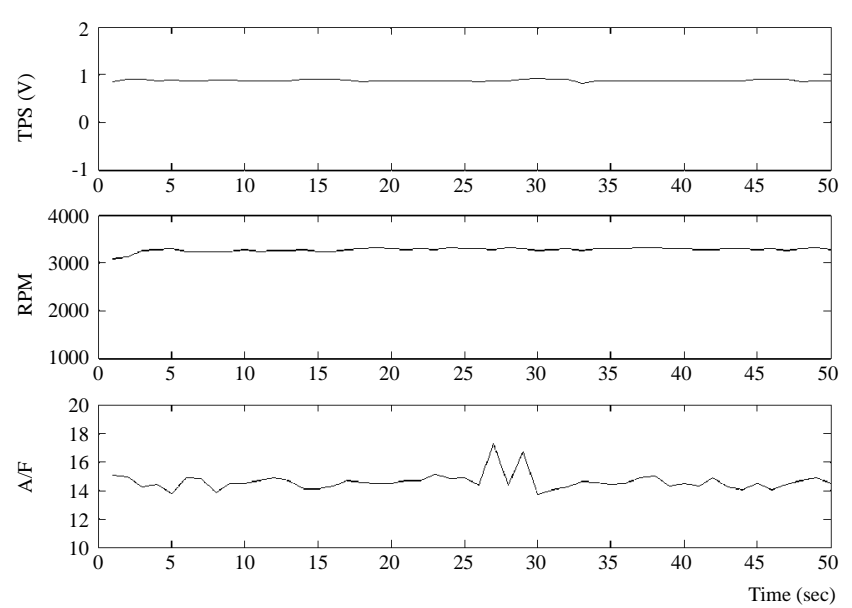

Fig. 10. Performance of the adaptive nonlinear motorcycle controller in a steady state operation.

age values in time history are shown in Table 2 . It shows that the emission under this condition satisfies the Taiwan motorcycle emission regulation which is almost the most rigorous around the world.

\section{CONCLUSION}

An adaptive nonlinear controller is applied in this research to control the air-fuel ratio of a motorcycle engine. The engine dynamics is highly nonlinear because it involves sophisticated dynamics processes and mutual-interaction. Besides, EGO sensor is used to measure the air-fuel ratio at exhaust pipe. The EGO sensor provides switching type feedback signal ( -1 or 1) to the controller. Thus, both the feedback signal and system dynamics are nonlinear, introducing a nonlinear
Table 2. Average values of the emission in idle operation and a steady state operation for the adaptive nonlinear controller

\begin{tabular}{lccc}
\hline Experiments & $\mathrm{CO}$ & $\mathrm{HC}$ & $\mathrm{NO}$ \\
\hline Idle operation & 0.543 & 120 & 54 \\
Steady state operation & 0.602 & 156 & 230 \\
\hline
\end{tabular}

control problem in their nature.

The proposed algorithm is validated through simulation and experiments. For the simulation, a motorcycle longitudinal dynamics model is developed to qualitatively discuss the performance of the algorithm. This model features engine, transmission, motorcycle inertia, and road load. On the other hand, for the experimental validation, an experimental setup featuring a real engine and a transmission from a KYMCO fuel injection type motorcycle was used. Effective road loading and inertia are also accounted in the setup.

The simulation results show that the proposed adaptive algorithm can track the intake air flow successfully, despite a substantial initial erroneous guess. After then, the intake air flow observer can quickly correct the estimate. Subsequently, the AFR control can obtain a good performance due to an accurate estimate of the intake air flow.

Finally, the experimental results show that the adaptive control algorithm introduces stable engine dynamics and satisfactory emissions. The idle speed variation meets the requirement of the motorcycle manufactures. The steady manoeuvres also feature stable engine speed. Most importantly, the AFR stays closely to the desired value and the emissions meet the Taiwan regulation which is rigorous compared to other regulations worldwide. In conclusion, an adaptive nonlinear control algorithm is successfully applied on a motorcycle engine for the control of air-fuel ratio. Furthermore, due to the success in air-fuel ratio control, the engine speed and emission including $\mathrm{CO}, \mathrm{HC}$ and NO can be maintained in a satisfactory level. In the future, more experiments featuring dramatic operation must be done to evaluate the performance of the control algorithm.

\section{ACKNOWLEDGEMENTS}

The study was supported by National Science Council of Taiwan under the granted funding of NSC922623-7-202-001-ET.

\section{REFERENCES}

1. Aquino, C.F., "Transient A/F Control Characteristics of 
A 5 Liter Central Fuel Injection Engine," SAE Paper 810494, Society of Automotive Engineers, New York (1981).

2. Arsie, I., Pianese, C., Rizzo, G., and Cioffi, V., "An Adaptive Estimator of Fuel Film Dynamics in the Intake Port of a Spark Ignition Engine," Control Eng. Pract., Vol. 11, pp. 303-309 (2003).

3. Choi, S.B. and Hedrick, J.K., "An Observer Based Controller Design Method for Improving Air/Fuel Characteristics of Spark Ignition Engines," IEEE T. Contr. Syst. T., Vol. 6, No. 3, pp. 325-334 (1998).

4. Fekete, N.P., Gruden, U.N., and Powell, J.D., "ModelBased Air-Fuel Ratio Control of a Lean Multi-Cylinder Engine," SAE Paper 950486, Society of Automotive Engineers, New York (1995).

5. Guzzella, L., Simons, M., and Geering, H.P., "Feedback Linearing Air/Fuel Ratio Controller," Control Eng. Pract., Vol. 5, No. 8, pp. 1101-1105 (1997).

6. Hendricks, E. and Sorenson, S.C., "Mean Value Modeling of Spark Ignition Engines," SAE paper 900616, Society of Automotive Engineers, New York (1990).

7. Hendricks, E. and Sorenson, S.C., "SI Engine Controls And Mean Value Engine Modeling," SAE paper 910258, Society of Automotive Engineers, New York (1991).

8. Hendricks, E., Hendricks, A., Jensen, A., and Sorenson, S.C., "Modeling of the Intake Manifold Filling Dynamics," SAE paper 960037, Society of Automotive Engineers, New York (1996).

9. Horie, K., Takahasi, H., and Akazaki, S., "Emissions Reduction During Warm-Up Period by Incorporating a Wall-Wetting Fuel Model on the Fuel Injection Strategy During Engine Starting," SAE paper 952478, Society of Automotive Engineers, New York (1995).
10. Kaidantzis, P., Rasmussen, P., Jensen, M., Vesterholm, T., and Hendricks, E., "Air-to-Fuel Ratio Control of Spark Ignition Engines using Gaussian Network Sliding Control," IEEE T. Contr. Syst. T., Vol. 6, No. 5 pp. 678687 (1998).

11. Kiencke, U. and Nielsen, L., Automotive Control Systems for Engine, Driveline, and Vehicle, Springer, Berlin (2003).

12. Moskwa, J.J. and Hedrick, J.K., "Modeling and Validation of Automotive Engines for Control Algorithm Development," J. Dyn Syst-T. ASME, Vol. 114, pp. 278285 (1992).

13. Pfeiffer, J.M. and Hedrick, J.K., "Nonlinear Algorithms for Simultaneous Speed Tracking and Air-Fuel Ratio Control in an Automobile Engine," SAE paper 990547, Society of Automotive Engineers, New York (1999).

14. Rosenberg, R.C. and Karnopp, D.C., "Introduction to Physical System Dynamics," McGraw-Hill Inc., Singapore (1996).

15. Souder, J.S., "Powertrain Modeling and Nonlinear Fuel Control," Master Thesis, Department of Engineering, U.C. Berkley, LA (1998).

16. Tseng, T.C. and Cheng, W.K., "An adaptive Air/Fuel Ratio Controller for SI Engine Throttle Transients," SAE paper 1999-01-0552, Society of Automotive Engineers, New York (1999).

17. Tunestal, P. and Hedrick, K., "Cylinder Air/Fuel Ratio Estimation Using Net Hear Release Data," Control Eng. Pract., Vol. 11, pp. 311-318 (2003).

18. Weeks, R.W. and Moskwa, J.J., "Automotive Engine Modeling for Real-time Control Using MATLAB/ SIMULINK," SAE paper 950417, Society of Automotive Engineers, New York (1995). 